\title{
The burden of trachoma in the rural Nile Delta of Egypt: a survey of Menofiya governorate
}

\author{
Gamal Ezz al Arab, Nagah Tawfik, Reda El Gendy, Wagida Anwar, Paul Courtright
}

\begin{abstract}
Background-Evidence of widespread distribution of trachoma in Egypt had not been clarified as previous surveys were limited to individual communities which may not have been representative of the general population. The Nile Delta of Egypt presents a unique environment for trachoma to persist. Economic improvements in the past decade have affected even the poorest rural environments; availability of electricity is now found in many rural communities. Availability of water in Nile Delta has always been good but poor hygienic conditions have been the primary factor in trachoma transmission. A survey of trachoma was undertaken in Menofiya governorate to determine if Egypt should be identified as trachoma endemic and targeted for trachoma control efforts.

Methods-A multistage random cluster study design was used with the target population defined as adults aged 50 and over and children aged 2-6 years from throughout the governorate. Among preschool children only trachoma was graded while among adults presenting visual acuity and cause of vision loss or blindness were also recorded. Adults were interviewed regarding past trichiasis surgery; those currently with trichiasis or a history of trichiasis surgery were also interviewed regarding outcome of surgery.
\end{abstract}

Results-A total of 3272 children aged 2-6 and 3322 adults age 50+ were enumerated. Among the children $81.3 \%$ were examined and among the adults $73.0 \%$ were examined. Active trachoma (follicles (TF) and/or intense inflammation (TI)) was found among $36.5 \%$ (95\% confidence interval (CI) $34.7-38.3 \%$ ) of the children. TI was 1.89 (95\% CI 1.22-2.94) times more common in rural children compared to urban children. The prevalence of trichiasis (TT) in adults was $6.5 \%$; women had an age adjusted odds of trichiasis of 1.68 (95\% CI 1.18-2.39) compared to men. Trichiasis was 2.11 times $(95 \%$ CI $1.33-$ 3.37) more common in rural Menofiya compared to urban Menofiya. TT accounts for blindness (presenting vision $<3 / 60$ ) in $8 \%$ of patients and accounts for
$13.2 \%$ of visual impairment. Overall, trichiasis surgical coverage was $34.4 \%$, slightly higher among men than women. The outcome of trichiasis surgery was poor in $44.4 \%$ of cases.

Conclusion-Trachoma is a serious public health problem in Menofiya governorate and a significant contributor to vision loss. These findings would suggest that continued poor hygienic conditions in rural Egypt have limited the reduction of active trachoma even in the face of significant improvements in socioeconomic status. Furthermore, the high proportion of trichiasis surgery cases with a poor outcome would indicate a need to reassess current surgical practices in Egypt and improve training and monitoring.

(Brf Ophthalmol 2001;85:1406-1410)

Research from the 1960s and earlier demonstrated a high prevalence of trachoma in selected governorates of Egypt. ${ }^{1-4}$ Trachoma was recognised to be a leading cause of blindness throughout the country, including Cairo. ${ }^{5}$ The Ministry of Health embarked upon a large scale antibiotic (tetracycline eye ointment) treatment programme in the 1960s and it was assumed that this programme led to a substantial decline in active trachoma in the targeted areas; soon thereafter the Ministry of Health declared that trachoma was no longer a public health problem in the country.

Trachoma research in a few small hamlets in Beheira governorate (south of Alexandria) and Qualyub governorate (north of Cairo) in the 1980 s suggested that, in some areas at least, trachoma re-emerged or continued to exist as a public health problem. In the Beheira hamlets active trachoma peaked at 59\% among children aged 3 and dropped off rapidly after age 5. ${ }^{6}$ Trachomatous trichiasis was detected in children as young as 10 years old and present in $57 \%$ of men and $75 \%$ of women over 40 years of age. Corneal opacities accounted for $40 \%$ of all blindness in these populations. Independent predictors of active disease in preschool children included absence of latrine, disease in school age children, and number of children in the household. ${ }^{7}$ Research in Qualyub focused on schoolchildren; while the prevalence of active disease remained high in 
this group (26\%), the peak of active disease is generally in the preschool age children. ${ }^{8}$ The ACT (Azithromycin for the Control of Trachoma) trials were conducted in the early 1990 s in some of the Beheira hamlets previously surveyed; baseline prevalence of active disease in $0-10$ year olds was $50.2 \% .^{9}$

Evidence of widespread distribution of trachoma in any governorate in Egypt had not been clarified as previous surveys were limited to individual communities which may not have been representative of the general population in selected governorates. Egypt is not officially recognised as having a public health problem with trachoma. Egypt presents a unique environment for trachoma to persist. Economic improvements in the past decade have affected even the poorest rural environments; availability of electricity is now found in many rural communities. Availability of water in Nile Delta has always been good but poor hygienic conditions have been the primary factor in trachoma transmission. In other settings in which socioeconomic status has increased (for example, Tunisia, Saudi Arabia, Oman) active trachoma has decreased rapidly. ${ }^{10}{ }^{11}$

Clarification of the distribution of trachoma (both active and cicatricial) is critical to long range planning for blindness prevention in Egypt. With global initiatives under way to eliminate trachoma as a public health problem, it was necessary to determine if Egypt should be considered a country requiring trachoma control programme activities or if Egypt should be considered free of trachoma. We undertook a survey of trachoma in Menofiya governorate (Nile Delta) to assist the Ministry of Health and relevant organisations determine if Egypt should be identified as trachoma endemic and targeted for trachoma control efforts.

\section{Methods}

STUDY DESIGN AND SAMPLING FRAME

Menofiya governorate, approximately $90 \mathrm{~min}-$ utes north west of Cairo on the road from Cairo to Alexandria, was chosen for the following reasons: socioeconomic and health services indicators are similar to the surrounding governorates; it has a dense compact population; it has well defined borders; there is no wide gap in the transition from rural to urban areas; there had been no survey or research related to trachoma in the governorate; and it was within easy reach of Cairo. A multistage random cluster study design was used. The survey target population was adults aged 50 and over and children aged 2-6 years from throughout the governorate. We chose these two groups as preschool children generally suffer the highest rates of active trachoma and are the primary target of control programmes, and adults $50+$ have the highest burden of trachomatous trichiasis and blindness. The total population for Menofiya governorate was estimated at 2.75 million in the last national census (1996).

SAMPLE AND SAMPLING

The sample was calculated on the assumption of a blindness rate of $2 \%$ of adults and an active disease prevalence of $40 \%$ in preschool children..$^{7-9}$ The sample was increased fivefold in order to account for village and household clustering of trachoma, to ensure a wide enough distribution throughout the governorate, and to provide enough residents with trichiasis and cataract to investigate surgical coverage and outcome. This generated a sample of 3000 adults and 3000 preschool children.

Census information from Menofiya governorate was used to create a sampling list of villages and their population. Clusters of similar size were created; large villages had multiple clusters. From this list 60 clusters were sampled, representing both urban and rural residents. Some villages had more than one cluster selected. Within each cluster, 50 households were selected (every fifth household using a door to door sampling method) to generate approximately 50 adults $(50+$ years of age) and 50 children (age 2-6). The governorate was divided into four geographical sectors covered by four field teams working at the same time which resulted in different areas being graded by different teams.

PILOT TESTING AND QUALITY CONTROL

Demographic, clinical, and interview forms were tested among a group of workers and villagers before the start of the survey. The 60 clusters were enumerated before the clinical examination. The enumeration included basic demographic and environmental factors of the household. Enumeration of the selected households was done 1-3 weeks before examination. All examinations were conducted by ophthalmologists following a standardised training and using the same equipment (torch and loupes for trachoma grading). All interviews were conducted by trained interviewers. Five clusters were re-examined following discrepancies noted for one team.

\section{FIELD PROCEDURES}

Before the survey, community promotion was done by holding a local general meeting with the governor, key health officials, local leaders, administrative representatives, nurses, and ophthalmologists to discuss the survey activities. The survey was approved by the local and national Ministry of Health and Population. Following training, 10 interviewers, 13 enumerators, 12 nurses, and 11 ophthalmologists were selected to participate in the fieldwork under supervision.

Among both preschool children and adults active trachoma was graded using the WHO simplified grading scheme. ${ }^{12}$ Vision was not recorded in children. Among adults (age 50+), presenting visual acuity was recorded; adults with vision $<6 / 18$ were evaluated for the cause of vision loss or blindness. Visual acuity was measured outside using E charts. Pinhole was used among adults with a vision $<6 / 18$. The senior ophthalmologist in each team conducted a fundus examination to decide the principal cause for low vision or blindness in cases with multiple causes. Corneal opacities were considered to be caused by trachoma only if there was a history of current or previous 
Table 1 Prevalence of active trachoma in children in Menofiya governorate

\begin{tabular}{lllll}
\hline & $\begin{array}{l}\text { TF/TI } \\
\text { present (\%) }\end{array}$ & $\begin{array}{l}\text { TF } \\
\text { present (\%) }\end{array}$ & $\begin{array}{l}\text { TI } \\
\text { present (\%) }\end{array}$ & Total \\
\hline Age (years) & & & & \\
2 & $188(35.3)$ & $154(28.9)$ & $34(6.4)$ & 533 \\
3 & $277(46.5)$ & $181(30.4)$ & $46(7.7)$ & 596 \\
4 & $194(37.5)$ & $162(31.3)$ & $32(6.2)$ & 517 \\
5 & $165(36.5)$ & $149(32.7)$ & $16(3.5)$ & 456 \\
6 & $198(35.4)$ & $172(30.8)$ & $26(4.7)$ & 559 \\
Total & $972(36.5)$ & $818(30.7)$ & $154(5.8)$ & 2661 \\
Sex & & & & \\
$\quad$ Male & $483(36.1)$ & $405(30.3)$ & $78(5.8)$ & 1337 \\
$\quad$ Female & $489(36.9)$ & $413(31.2)$ & $76(5.7)$ & 1324 \\
Residence & & & & \\
$\quad$ Urban & $322(41.8)$ & $294(38.2)$ & $28(3.6)$ & 770 \\
$\quad$ Rural & $650(34.4)$ & $524(27.7)$ & $126(6.7)$ & 1891 \\
\hline
\end{tabular}

trichiasis or trachomatous pannus. Adults were interviewed regarding past trichiasis surgery; those currently with trichiasis or a history of trichiasis surgery were also interviewed regarding outcome of surgery.

Most examinations and interviews were done at the household. Households with missed eligible people were identified and members asked to join the medical team for examination at a central facility (in most clusters this was the village health unit) in the village on a subsequent day. Clusters with low $(<70 \%)$ coverage of either children or adults were targeted for follow up 3 weeks after the completion of the survey.

\section{STATISTICAL ANALYSIS}

Statistical analyses were done on STATA for Windows version 6.0 (Stata Corp, TX, USA). For this descriptive study $\chi^{2}$ statistics (with odds ratios and $95 \%$ confidence intervals) were calculated. Findings were adjusted for age and sex (Mantel-Haenszel) as indicated. Clustering of active trachoma in children was expected and clustering was accounted for in the confidence intervals for the data on active disease in preschool children. The Svylogit procedure was employed in simple and multiple logistic regression analyses in order to take into account clustering of cases in the sample.

\section{Results}

The 60 selected clusters came from 49 communities from throughout Menofiya. Similar to the population distribution of Menofiya 49 (82\%) of 60 clusters were rural and $11(18 \%)$ were

Table 2 Risk factors for prevalence of active trachoma in children in Menofiya governorate

\begin{tabular}{lllll}
\hline & TF/TI present (\%) & TF present (\%) & TI present (\%) & Total \\
\hline Type of building & $386(33.7)$ & $308(26.9)$ & $78(6.8)$ & 1144 \\
Mud/wood & $576(38.7)$ & $501(33.7)$ & $75(5.0)$ & 1487 \\
Stone/cement & $0.80(0.66-0.97)^{\star}$ & & $1.38(0.96-1.97)$ & \\
OR (95\% CI) & & & $8(4.3)$ & 188 \\
Source of water & $39(20.7)$ & $31(16.5)$ & $121(5.8)$ & 2090 \\
$\quad$ Piped village tap & $789(37.8)$ & $668(32.0)$ & $6(5.4)$ & 111 \\
Piped household tap & $48(43.2)$ & $42(37.8)$ & $10(11.9)$ & 84 \\
Village well & $28(33.3)$ & $18(21.4)$ & $8(5.8)$ & 137 \\
Household well & $47(34.3)$ & $39(28.5)$ & 6.5 & \\
Canal & $24.4^{\star \star}$ & & & \\
$\chi^{2}$ & $174(46.4)$ & $163(43.5)$ & $11(2.9)$ & 375 \\
Latrine & $708(36.0)$ & $583(29.6)$ & $125(6.4)$ & 1968 \\
General network & $48(22.3)$ & $39(18.1)$ & $9(4.2)$ & 215 \\
Latrine in house & $31(41.3)$ & $23(30.7)$ & $8(10.7)$ & 75 \\
Latrine outside house & & $\chi^{2}=11.0^{\star}$ & \\
Other & $\chi^{2}=35.5^{\star \star}$ & & & \\
$\chi^{2}$ & & &
\end{tabular}

${ }^{\star} \mathrm{p}<0.01,{ }^{\star \star} \mathrm{p}<0.001$
Table 3 Trachomatous trichiasis in adults in Menofiya governorate

\begin{tabular}{lllll}
\hline & $\begin{array}{l}\text { All trichiasis } \\
\text { No(\%) }\end{array}$ & $\begin{array}{l}\text { Bilateral } \\
\text { trichiasis } \\
\text { No (\%) }\end{array}$ & $\begin{array}{l}\text { Unilateral } \\
\text { trichiasis } \\
\text { No (\%) }\end{array}$ & $\begin{array}{l}\text { Total } \\
\text { No }\end{array}$ \\
\hline Males & $54(5.0)$ & $28(2.6)$ & $26(2.4)$ & 1082 \\
$\begin{array}{l}\text { Females } \\
\text { Residence }\end{array}$ & $104(7.7)$ & $63(4.7)$ & $41(3.1)$ & 1344 \\
$\quad \begin{array}{l}\text { Urban } \\
\text { Rural }\end{array}$ & $24(3.7)$ & $11(1.7)$ & $13(2.0)$ & 648 \\
\hline
\end{tabular}

urban. Although our target was 3000 children and 3000 adults, a total of 3272 children and 3322 adults were enumerated. Among the enumerated children 2661 were examined $(81.3 \%)$; among the enumerated adults 2426 (73.0\%) were examined. Among adults, working age men (aged 50-59 years) had the lowest response rate $(62.1 \%$, data not presented).

\section{ACTIVE TRACHOMA}

Overall, active trachoma defined as the presence of follicles (TF) and/or intense inflammation (TI) was found among $36.5 \%$ (95\% confidence interval (CI) $34.7-38.3 \%$ ) of the children, with the highest prevalence among children aged 3 (Table 1). The prevalence of intense inflammation (TI) was $5.8 \%(95 \% \mathrm{CI}$ $4.9-6.7 \%)$. The prevalence of active trachoma (TF or TI) was more common in children in urban areas compared to rural areas, however, TI was 1.89 (95\% CI 1.22-2.94) times more common in rural children compared to urban children. Using the WHO definition of a $20 \%$ or more prevalence of active trachoma as a public health problem, 28 of the 48 villages $(58.3 \%)$ in the survey would be identified as having trachoma as a public health problem. Trachomatous scarring was recognised in 200 children $(7.5 \%)$; none had trichiasis or corneal opacity. Besides residence (rural/urban), factors associated with active disease in children in the governorate included sanitation (latrine), water supply, and type of building; source of income and TV/radio were not associated with active disease (Table 2).

\section{CICATRICIAL TRACHOMA AND BLINDNESS IN}

ADULTS

In our survey of adults 50 years and over almost all adults had evidence of conjunctival scarring. The prevalence of trichiasis in adults was $6.5 \%$. Trachomatous trichiasis was associated with both age and sex; women had an age adjusted odds of trichiasis of 1.68 (95\% CI 1.18-2.39 $\mathrm{p}=0.004$ ) compared to men (Table $3)$. The age adjusted odds of bilateral trichiasis was 1.92 (95\% CI 1.19-3.09 $\mathrm{p}=0.006)$ times higher in females compared to males while the odds of unilateral trichiasis in women was only 1.36 (95\% CI 0.890-2.31) times that of men. Trichiasis was 2.11 times (95\% CI 1.33-3.37) more common in rural Menofiya compared to urban Menofiya. Bilateral trichiasis, in particular, was associated with rural residence (OR=2.71, 95\% CI 1.39-5.42 p=0.002).

Trichiasis accounts for blindness (presenting vision $<3 / 60$ ) in $8 \%$ of patients and accounts for visual impairment in $13.2 \%$ of patients. Cataract and other corneal opacities are the 
Table 4 Trichiasis surgical coverage among adults in Menofiya governorate

\begin{tabular}{llll}
\hline & $\begin{array}{l}\text { All trichiasis } \\
\text { surgery/total (\%) }\end{array}$ & $\begin{array}{l}\text { Bilateral trichiasis } \\
\text { surgery/total (\%) }\end{array}$ & $\begin{array}{l}\text { Unilateral trichiasis } \\
\text { surgery/total (\%) }\end{array}$ \\
\hline Males & $14 / 27(51.9)$ & $10 / 18(55.6)$ & $4 / 9(44.4)$ \\
Age 50-59 & $8 / 27(29.6)$ & $7 / 18(38.9)$ & $1 / 9(11.1)$ \\
Age 60-69 & $9 / 31(29.0)$ & $5 / 14(35.7)$ & $4 / 17(23.5)$ \\
Age 70+ & $31 / 85(36.5)$ & $22 / 50(44.0)$ & $9 / 35(25.7)$ \\
Subtotal & & & \\
Females & $19 / 63(30.2)$ & $15 / 43(34.9)$ & $4 / 20(20.0)$ \\
Age 50-59 & $20 / 56(35.7)$ & $14 / 35(40.0)$ & $6 / 21(28.6)$ \\
Age 60-69 & $13 / 37(35.1)$ & $9 / 23(39.1)$ & $4 / 14(28.6)$ \\
Age 70+ & $52 / 156(33.3)$ & $38 / 101(37.6)$ & $14 / 55(25.5)$ \\
Subtotal & $83 / 241(34.4)$ & $60 / 151(39.7)$ & $23 / 90(25.6)$ \\
Total & & &
\end{tabular}

Table 5 Recurrence of trichiasis among people who have had trichiasis surgery

\begin{tabular}{lll}
\hline & $\begin{array}{l}\text { Recurrence } \\
\text { No } \% \text { \%) }\end{array}$ & $\begin{array}{l}\text { No recurrence } \\
\text { No (\%) }\end{array}$ \\
\hline $\begin{array}{ll}\text { Males } \\
\quad \text { Age 50-59 }\end{array}$ & $7(29.2)$ & 17 \\
$\quad$ 60-69 & $7(46.7)$ & 8 \\
$\quad 70+$ & $6(42.9)$ & 8 \\
Total & $20(37.7)$ & 33 \\
$\begin{array}{l}\text { Females } \\
\quad \text { Age 50-59 }\end{array}$ & $16(47.1)$ & 18 \\
$\quad$ 60-69 & $12(35.3)$ & 22 \\
$70+$ & $12(54.6)$ & 10 \\
Total & $40(44.4)$ & 50 \\
\hline
\end{tabular}

only other causes of blindness more common than trachoma. Among all trichiasis cases, women are 1.67 times (95\% CI $0.67-4.3$ ) more likely to be blind (presenting vision $<6 / 60$ ) compared to men (age adjusted). Similarly, visual impairment (presenting vision $<6 / 18$ ) is more common in female trichiasis patients (age adjusted odds ratio $=1.73(95 \%$ CI 0.76-4.01)) than male trichiasis patients.

TRICHIASIS SURGICAL COVERAGE

Trichiasis surgical coverage was defined as the proportion of those with trichiasis (or a past history of trichiasis) who have had surgery. Overall, trichiasis surgical coverage is $34.4 \%$, slightly higher among males $(36.5 \%)$ than females $(33.3 \%)$ (Table 4$)$. As expected, surgical coverage for unilateral trichiasis was lowest (25.6\% overall, no difference by sex). Among males most in need of trichiasis surgery (bilateral trichiasis) surgical coverage is highest among the youngest group while it is lowest among the youngest females with bilateral trichiasis, although the differences were not statistically significant.

Even though there was relatively good surgical coverage compared to other settings, the outcome of trichiasis surgery (recurrence of trichiasis following surgery) was poor in $44.4 \%$ of cases (Table 5). Recurrence was slightly higher among women.

\section{Discussion}

Trachoma is a serious public health problem in Menofiya governorate, and likely to be common in surrounding governorates in the Nile Delta of Egypt. It should be noted that the prevalence of active disease is less than was found in previous surveys. This may be because trachoma, although endemic in Menofiya, has never been as severe as in Beheira (to the north) or Quyalub (to the south west). The lower prevalence may also be due to improved socioeconomic status and water and sanitation conditions; $80 \%$ of preschool children in Menofiya have access to piped water in their households and $89 \%$ of children have access to a latrine in the house. In the Beheira governorate study hamlets in the mid-1980s there was no piped water or electricity (except battery power) and only $47 \%$ of households had a latrine in the house. Although no studies of flies were carried out, eye seeking flies are still common in Nile Delta villages generally because of continued poor hygienic conditions. Our findings may have been biased due to grader error; however, there was no variation between teams with the final data set (including re-examination of a number of villages) and variation between graders is unlikely to contribute to our findings.

The high prevalence of active disease in some urban areas was not anticipated; however, urbanised areas of Menofiya governorate have similar sanitation and hygiene conditions. It is possible that the high population density in these urbanised areas had led to high transmission. Although there are some differences in grading techniques between the current survey (WHO simplified trachoma grading) and the previous Beheira survey blindness in the future in Menofiya may not be as high as previously suggested. ${ }^{6}$ Nevertheless, trachoma remains a significant contributor to vision loss in Menofiya. As intense inflammation (TI) is probably a better predictor of severe conjunctival scarring and trichiasis in adults, ${ }^{13}$ efforts are needed to reduce TI, particularly in rural Menofiya. Our findings would suggest that continued poor hygienic conditions in rural Egypt have limited the reduction of active trachoma even in the face of significant socioeconomic growth.

Trachomatous trichiasis is a significant public health problem affecting $5.0 \%$ of men and $7.7 \%$ of women aged 50 and over. Targeting surgical intervention for all cases of trichiasis (projected to be at least 24000 people in Menofiya alone) may be difficult. Surgical intervention may be most reasonably targeted at those people with bilateral trichiasis, who account for $58 \%$ of the total trichiasis. Among this group, women account for $69 \%$ of the total. As vision loss and blindness are more common in bilateral trichiasis patients, in women, and in rural areas, community based programmes directed at women's groups may be the most effective in reducing blindness due to trachoma. The high proportion of trichiasis cases with a poor outcome would indicate a need to reassess current surgical procedures (the Snellen procedure) and training in bilamellar tarsal rotation.

These findings indicate the need for large scale trachoma control activities in selected Nile Delta governorates in Egypt. The absence of information on trachoma in upper Egypt (from Cairo to the Sudan border) is needed before recommending creation of trachoma control efforts there. In late 2000, the Ministry of Health recognised trachoma as a public health problem in Egypt and trachoma control efforts have been initiated in Menofiya. 
The Menofiya Blindness and Trachoma Survey was supported by Pfizer Inc, the $\mathrm{Al}$ Noor Foundation, the Ministry of Health Centre for Epidemiologic and International Ophthalmology to whom we are grateful. This project could not have been carried out without the support of the governor, health officials, and population of Menofiya. In particular, the authors are grateful or the support from Professor Dr Ismail Salam, minister MOH We are also grateful for the assistance provided by Ahmed Mousa (biostatistician) and Sayed Hanafy (data manager) of the Al Noor Foundation, and Dr Ahmed El Hakim (director, External Affairs and Health Policy) of Pfizer Egypt.

1 Meyerhof $M$. The history of trachoma treatment in antiquity and during the Arabic middle ages. Bulletin of the Ophthalmologic Society of Egypt 1936:26-51.

2 Attiah, MAH, El-Kholy AM. A study of self mass treatment of trachoma in Qalyub, UAR, 1961. Bulletin of the Ophthalmologic Society of Egypt 1963;56:18-39.

3 Attiah, MAH. The main subjects trachoma and acute ophthalmia the evolution of the treatment of trachoma. Acta First Afro-Asian Congress of Ophthalmology, Cairo 1958:115.

4 Said M-E, Goldstein H, Korra A, et al. Visual acuity as related to causes of blindness, age and sex in urban and related to causes of blindness, age and sex in urban
rural Egyptians. Am f Public Health 1971;61:2433-48.
5 International Eye Foundation. Findings from the South Cairo Eye Disease Survey: Integrated Urban Primary Eye Care Program. Bethesda, MD: International Eye Foundation, 1985.

6 Courtright P, Sheppard J, Schachter J, et al. Trachoma and blindness in the Nile Delta: current patterns and projections for the future in the rural Egyptian population. Br f Ophthalmol 1989;73:536-40.

7 Courtright P, Sheppard J, Lane S, et al. Latrine ownership as a protective factor in inflammatory trachoma in Egypt. $\mathrm{Br} \mathcal{F}$ Ophthalmol 1991;75:322-5.

8 Barsoum IS, Mostafa MSE, Shihab AA, et al. Prevalence of trachoma in school children and ophthalmological outpatients in rural Egypt. Am f Trop Med Hyg 1987;36:97patients

9 Schachter J, West SK, Chandler RD, et al. Azithromycin in control of trachoma. Lancet 1999;354:630-5

0 Tabbara KF, Al-Omar OM. Trachoma in Saudi Arabia. Ophthalmic Epidemiol 1997;4:127-40.

11 Khandekar R. National blindness survey. Ministry of Health, Muscat, Oman.

12 Thylefors B, Dawson C, Jones B, et al. A simple system for assessment of trachoma and its complications. Bull World Health Organ 1987;65:477-83.

13 Hsieh YH, Bobo LD, Quinn TC, et al. Risk factors for trachoma: 6-year follow-up of children aged 1 and 2 years. Am f Epidemiol 2000;152:204-11.

\section{Contributors please note:}

Communications from all countries except the UK and Republic of Ireland should be sent to Professor C Hoyt, Editor, British fournal of Ophthalmology, University of California, Department of Ophthalmology, 10 Kirkham Street, K 301, San Francisco, CA 94143-0730, USA (tel: 001415 502-6871; fax: 001415 514-1521).

Manuscripts from the UK and the Republic of Ireland should be sent to Professor Andrew Dick, UK Editor, British fournal of Ophthalmology, Division of Ophthalmology, University of Bristol, Lower Maudlin Street, Bristol BS1 2LX (tel: +44 (0) 0117 929-4496; fax: +44 (0) 117 929-4607). 